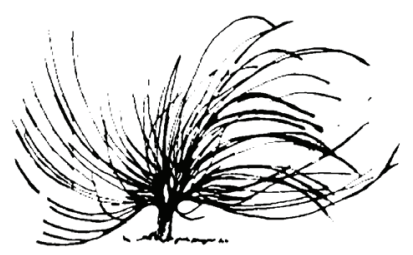

\title{
Los aventurados en el espacio digital: Desde la máquina de escribir al correo electrónico
}

\section{Venturesome in the Digital Space: From the Typewriter to Email}

Denise Hernández y Hernández ${ }^{1}$

\begin{abstract}
Resumen
En este artículo reconstruimos la historia de los primeros encuentros con la tecnología (máquina de escribir, computadora, internet y correo electrónico) de un grupo de estudiantes de posgrado en el extranjero (en Barcelona, España). Los datos que presentamos corresponden a la historia reconstruida a través de una serie de entrevistas sobre cómo recordaban su primer contacto con las computadoras: en qué época de su vida sucedió esto, cuántos años tenían, cómo aprendieron a utilizarlas, si recibieron instrucción formal o aprendieron por su cuenta. También se indagó sobre las cuentas de correo electrónico: cuándo abrieron su primera cuenta, quién les ayudó a hacerlo, cómo se enteraron de lo que era una cuenta de correo. Por último, rescatamos su opinión general sobre la tecnología: qué piensan sobre ella, qué ventajas o desventajas han percibido, cómo ven su relación con las TIC en un futuro.
\end{abstract}

1 Doctora en Comunicación Lingüística y Mediación Multilingüe, por la Universidad Pompeu Fabra (Barcelona, España), adscrita al Programa de Investigación e Innovación en Educación Superior de la Universidad Veracruzana. 
Palabras clave: TIC, internet, correo electrónico, literacidad, estudiantes.

\begin{abstract}
In this study, we analyzed the history of the first contact of a group of graduate students in Barcelona, Spain, with Information and Communication Technologies (ICT) which includes the typewriter, computer, the Internet, and email. Data provided in this research were collected through interviews designed to recover information regarding: the student's first experience with computers, the mechanisms used to learn how to use them, whether they learnt by themselves or were guided by an instructor, and the student's age at the beginning of this process. We also were interested in understanding the learning process with email accounts: the first time students opened their accounts, whether students received or not assistance, and how did they find out what an email account was. Finally, we recovered their opinions about the ICT.
\end{abstract}

Keywords: ICT, Internet, email, literacy, students

\title{
Introducción
}

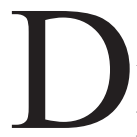

ebido a la necesidad de conocer el impacto que tuvieron las tecnologías de información y comunicación (TIC) en las prácticas letradas de un grupo de personas adultas profesionales en el extranjero, se llevó a cabo este trabajo. La investigación se inserta dentro de los llamados nuevos estudios de literacidad (NEL). Son una corriente joven que ha influido en las investigaciones sobre alfabetización, se abordan desde perspectivas teóricas hasta implicaciones en el ámbito educativo; se describe detalladamente cómo utilizamos determinados textos en situaciones y momentos concretos, en comunidades particulares y con objetivos específicos para alcanzar un propósito explícito (Barton y Hamilton, 1998; Camitta, 1993; Gee, 1999; Kalman, 1999, 2004; Kress, 2003; Lankshear, Gee, Knobel y Searle, 1997; Scribner y Cole, 1981; Street, 1993, 1995).

Los NEL adoptan una mirada global, sociocultural; intentan no excluir ningún aspecto sobre la vida de los sujetos y su relación con las prácticas de literacidad. Se toma en cuenta el ámbito social, cultural y 
el momento histórico donde se desarrolla la actividad comunicativa. Dentro de los NEL la propuesta más completa y apreciada es la de Barton y Hamilton (2004), quienes analizan seis principios sobre la naturaleza de la literacidad desde la teoría social:

1. La literacidad es entendida como un conjunto de prácticas sociales, que se pueden inferir de los eventos mediados por los textos escritos.

2. Hay diferentes literacidades asociadas con diferentes dominios de la vida.

3. Las prácticas letradas son reguladas por instituciones sociales y por relaciones de poder, algunas se vuelven más dominantes, visibles e influyentes que otras.

4. Las prácticas de literacidad cumplen objetivos y están insertas en prácticas sociales y culturales más amplias.

5. La literacidad está socialmente situada.

6. Las prácticas de literacidad cambian y algunas otras son adquiridas a través de procesos informales de aprendizaje y de construcción de sentido.

Lo que presentamos en este artículo son los primeros acercamientos de 10 informantes con las computadoras y con los nuevos espacios y lenguajes digitales en redes sociales. De igual forma tratamos de averiguar cómo enfrentaron los retos que esta tecnología representa y de qué forma los resolvieron.

\section{Metodología}

El grupo de informantes estuvo constituido por 10 personas de edades entre los 24 y 38 años, de nacionalidad mexicana (siete varones y tres mujeres), ocho estuvieron en Barcelona por estudios de maestría o de doctorado y dos laboran profesionalmente (sin embargo, su llegada al extranjero fue por motivos de estudio). Su participación fue voluntaria.

Se realizaron un total de 27 entrevistas (del 2008 al 2012), con una duración aproximada de una hora. En las transcripciones solo marcamos algunos rasgos suprasegmentales, están escritas en español estándar con normativa escrita, pese a que el discurso oral tenga otro tipo de sintaxis. En la tabla 1 presentamos el código de transcripción empleado. 
Tabla 1

Código de transcripción

\begin{tabular}{|c|l|}
\hline SÍMBOLO & \multicolumn{1}{|c|}{ DESCRIPCIÓN DEL SIGNIFICADO CODIFICADO } \\
\hline$[\mathrm{xxx}]$ & Discurso del entrevistador \\
\hline$\ldots-$ & Palabra incompleta \\
\hline$:$ & Alargamiento de palabra \\
\hline$\ldots$ & Pausa larga \\
\hline, & Pausa corta \\
\hline XXX & Discurso incomprensible \\
\hline$[$ MAYÚSCULA] $]$ & $\begin{array}{l}\text { Indicaciones de lo que pasaba en la entrevista o aclaración de } \\
\text { algún hecho }\end{array}$ \\
\hline Cursiva & Cambio de idioma \\
\hline$/ \mathrm{xxx} /$ & Transcripción fonética \\
\hline$\underline{\mathrm{xxx}}$ & Discurso de una tercera persona \\
\hline
\end{tabular}

Nota: Elaboración propia.

El tipo de transcripción aplicada fue la siguiente:

- Hemos transcrito las interacciones tanto del discurso de los sujetos informantes, como los de la entrevistadora.

- La transcripción sigue las normas ortográficas convencionales, pero no se utilizan todos los símbolos de puntuación tradicionales, se limita a respetar las pausas y alargamientos producidos por los sujetos informantes.

- No se corrigieron las construcciones gramaticales incorrectas desde punto de vista de la normativa, con la idea de mantener el carácter genuino de las reflexiones.

- Se consideraron algunos aspectos proxémicos relevantes para contextualizar la transcripción.

- $\quad$ No se consideraron aspectos paraverbales.

Conformamos 15 categorías y 49 subcategorías del trabajo total (las primeras se encuentran en mayúsculas y las segundas en minúsculas). Sin embargo, aquí solo presentamos tres categorías y algunas de sus 
subcategorías correspondientes, debido a que son las que muestran los datos que nos permiten reconstruir esta historia. Mostramos una breve descripción de cada una de ellas:

- CONTACTO CON COMPUTADORAS: Se describe la historia del encuentro de los informantes con la tecnología.

- Máquina de escribir: Si utilizaron la máquina de escribir, qué tipo de textos realizaban, recibieron clases de taquimecanografía, cómo vivieron el cambio de la máquina a la computadora.

- Primera computadora: Cuándo tuvo una propia en casa, de uso personal o compartida.

- Cursos: Clases o cursos formales o informales que recibieron en la escuela o en centros particulares.

- $\quad$ Primeras actividades: Ejercicios, juegos o búsquedas que realizaba en la computadora.

- $\quad$ Actualización de computadora: Cómo se ha llevado a cabo el cambio de sus aparatos tecnológicos o bien los criterios que utilizan para realizar este cambio.

- Creencias y pensamientos sobre uso de tecnología: Qué pensamientos y creencias surgieron cuando tuvieron contacto con la tecnología y cómo ha ido cambiando estas a través del tiempo.

- CONECTIVIDAD: Se describe el encuentro de los informantes con internet.

- Primer contacto internet: Cuándo y cómo fue su primer contacto con internet, qué información buscaba o para qué lo utilizaba.

- Internet en casa: Cuándo tuvieron internet por primera vez en casa y cómo fue esta experiencia.

- Buscadores: Cuáles utilizan para consultar información.

- CORREO ELECTRÓNICO: Se describe el encuentro de los informantes con el correo electrónico.

- Primer contacto correo electrónico: Cuándo y cómo fue su primer contacto con el correo electrónico.

\section{Resultados}

Por cuestiones de espacio solo podemos mostrar un ejemplo de cada período (primaria, secundaria y bachillerato) en donde nuestros sujetos informantes tuvieron su primer contacto con las computadoras, 
así como dónde y cómo sucedió esto. Sin embargo, en el apartado de "reflexiones" retomaremos los datos de los 10 casos. Consideramos relevante incluir la voz de cada informante, por lo que incluimos partes de las transcripciones de las entrevistas.

\section{En primaria...}

Sol asistió a una primaria privada con una infraestructura privilegiada. Durante la secundaria, preparatoria y principios de la universidad llegó a realizar sus trabajos escolares en máquina de escribir, tuvo una máquina mecánica que no utilizó mucho, porque sus padres pudieron comprarle después una eléctrica; de hecho, tomó un curso de mecanografía.

Asistió a la misma escuela desde la primaria hasta el bachillerato y recibió clases de computación de sexto de primaria hasta bachillerato; recuerda que le enseñaron el sistema operativo MS-DOS y fue hasta la universidad que tomó clases particulares donde le enseñaron a usar la paquetería básica de Office y el AutoCAD; también aquí le enseñaron a navegar por internet. La primera computadora que hubo en su casa fue cuando cursaba la universidad, pero estaba en la habitación de su hermano, por lo que se suponía era de él, y ella la ocupaba de vez en cuando. En esta época su papá contrató el servicio de internet. Su hermano le enseñaba también algunas cosas sobre navegación:

... mi hermano fue un poco como el primero así que ma...- que él sabía más y me iba enseñando me decía 'si puedes navegar' lo que era navegar lo que era hacer una búsqueda en el Yahoo y, que se podían buscar cosas y bajarte de páginas y cosas así él fue, como el primero que me em...- empezaba a enseñar de dónde lo sabía él no sé. [SO/1/2]

Tiene la sospecha de que tal vez fue su hermano quien le ayudó a sacar su primera cuenta de correo; estaba por terminar la licenciatura cuando abrió una y la razón fue la siguiente:

... era que me iba yo a venir aquí a Barcelona [aja] entonces estaba yo empezaba a buscar universidades empezaba a buscar dónde irme a estudiar y todo eso y para contactarme con la gente 
y, con las universidades les escribía un e-mail y por eso me saqué la cuenta de correo. [SO/1/2]

La razón principal por la cual decide cambiar de máquina es porque esta se ha descompuesto. Si ve que no es tan costosa la inversión decide mandarla a reparar, de lo contrario prefiere comprar una nueva.

\section{En secundaria...}

El caso de Noé resulta interesante:

... en el pueblo no había computadoras de hecho [mju] te estoy hablando de alrededor del noventai:, cuatro, de 1994 más o menos, que yo debí de haber estado en la: secundaria seguramente o iniciando la, la secundaria, primero, segundo de secundaria, por ahí [si] eh:, en ese tiempo recuerdo que ahí en el, en Ocotlán había un: pintor muy famoso que se llama Rodolfo Morales, él era más conocido aquí en, en Europa general y no en el pueblo, en el pueblo la i...- la gente tenía la idea de que él estaba loquito y que por eso pintaba, por eso pintaba, resulta que este, esta persona al venir a Europa eh, escucha hablar de computadoras, de libros y una serie de cosas, regresa a Ocotlán a instalarse ya de por vida, yo creo que eh: por ahí de: los 90 [mju] principios de los 90 y entonces llega con una serie de ideas muy innovadoras y él puso el primer este, laboratorio por [de café o qué] si, no laboratorio digamos de, de computación ahí en su casa [ah] entonces debió de haber tenido alrededor de 20 computadoras, entonces todos los chavitos íbamos a, a esa casa [mju] a aprender este a utilizar las computadoras, el señor este Rodolfo Morales, él eh: pagaba a maestros que iban desde Oaxaca hasta Ocotlán, no está muy lejano pues, pero iban ahí y nos daban cursos ¿no? pero en ese tiempo era el MS-DOS [mju] ¿no? que yo la verdad no me acuerdo cómo se utilizaba eso, ahí tuve mi primer contacto con las computadoras. [NO/1/1]

Además del legado de su obra artística, Rodolfo Morales desarrolló una carrera altruista a través de su Fundación, ubicada en su propia casa como lo menciona Noé. A parte de las clases de computación había torneos de ajedrez, clases de pintura, conciertos y una biblioteca, todo gratis para la juventud. Noé dice que fue ahí donde tuvo su primer contacto fuerte con la computadora; les enseñaron el sistema operativo MS-DOS, pero no recuerda muy bien de qué trataba esto. 
En su secundaria no había computadoras, por lo que Noé acudía a la Fundación para seguir aprendiendo. Lo que sí llevaba en la escuela era clases de taquimecanografía y esto le facilitó la escritura cuando pasó de la máquina de escribir a la computadora, porque podía utilizar todos los dedos al teclear. Estando en secundaria y bachillerato utilizó una Olivetti muy vieja para hacer sus trabajos; incluso las primeras tareas escolares de la universidad también las realizó en una máquina de escribir, pero ya era una eléctrica, porque vivía con un cura que se la prestaba.

Sin embargo, Noé afirma que entonces "no se veía bien" si entregaba así sus trabajos, con máquina de escribir, por eso iba a hacerlos con sus amigos que tenían computadora o a un cibercafé. Así aprendió a utilizar el procesador Word, aunque lo justo para hacer sus trabajos escolares. Lo que le habían enseñado en la Fundación no le sirvió después, porque ya el sistema operativo MS-DOS "había pasado a la historia".

Al terminar el bachillerato se mudó a Chihuahua para ingresar a un seminario (se preparaba para ser sacerdote), aquí comenzó a manejar la paquetería de Office, porque tenía que entregar trabajos más elaborados. Al poco tiempo abandonó el seminario y se fue a Puebla a estudiar la licenciatura, tuvo su primera computadora portátil y en la misma universidad recibió un curso básico de cómputo. Además, asistió a una escuela privada donde le enseñaron a manejar el Office 2003 y también recibió clases en la Universidad Nacional Autónoma de México (UNAM). En el 2007 se compró una Mac, en este mismo año llega a Barcelona.

Recuerda que la primera vez que tuvo acceso a internet fue en 1999, cuando estaba aún en el seminario, buscaba información para sus tareas escolares porque los maestros comenzaban a exigirle trabajos con una mejor presentación:

... entonces en ese tiempo, ahí en el seminario también este, ya comenzaba a haber este, computadoras entonces, nos daban acceso a las, al Internet [mju] pero sólo por un tiempo limitado porque como es un seminario y tenían miedo de que viéramos páginas pornográficas [estaban controlados] entonces estábamos controlados ¿no? y ahí fue cuando tuve por primera vez acceso a la, a al Internet, en el 2000 cuando ingresé a la Ibero, fue cuando Internet ya, empezó a formar parte prácticamente de, de mi vida. [NO/1/3] 
Obtuvo su primera cuenta de correo electrónico también cuando estaba en el seminario; un alumno más avanzado le ayudó a abrirla:

... [entonces, para, tu primera cuenta de correo] fue en: Yahoo [en Yahoo] sí [por esa fecha igual] sí, sí, 99, 2000 más o menos, sí, que por cierto, era todo un caos ¿no? porque yo no sabía cómo este, cómo utilizarlo ¿no? [o se...- ¿la abriste tú por tu cuenta o alguien?] no la primera vez alguien me lo abrió, un compañero de ahí mismo, de, de, sí de los viejitos del seminario, sí, de los chavos ya grandes [mju] que: era:, estaba como en tercero o cuarto de filo...- de Teología, es decir ya los grandes, grandes, porque a ellos como ya eran, se supone que grandes les daban mayor este [acceso, libertad] acceso, acceso y libertad ¿no? Entonces ellos eran los que de alguna manera ya sabían, nosotros no tanto [mju] Entonces por primera vez él me la abrió, y la utilizaba muy poco porque me costaba trabajo [mju] ya en el 2000 sí ya este, tuve otra cuenta de Yahoo y ahí ya como ya tenía acceso constante y a cualquier hora pues entonces ya, ahí picándole que enviando que no sé qué, que no sé cuándo, pues ya este, aprendí a, a utilizarlo mejor. [NO/1/4]

Noé ha reflexionado sobre la cantidad de tecnología de la cual disponemos ahora y tiene la impresión que de alguna forma hemos perdido la calidad y el contacto humano:

... sí hoy tenemos tantas herramientas para comunicarnos, que al final de cuentas, a veces, ya hemos perdido la capacidad de llegar a la otra persona, este, de platicar directamente, es decir, el el contacto físico, la cercanía. [NO/1/6]

Observó un fenómeno peculiar al ponerse de moda el uso de internet: sus amigos poco a poco se fueron alejando entre sí, sustituyeron el contacto físico por el virtual y el resultado no fue lo que esperaban; a tal grado que después de un tiempo decidieron combinar ambas cosas: la tecnología y la cercanía humana. Según su experiencia con jóvenes adolescentes (trabajó como maestro en un bachillerato y también en una casa-hogar con niños de la calle), estos grupos también prefieren el contacto con sus pares, a pesar de tener acceso a las computadoras 
muchas veces prefirieron irse con él o ella a jugar un partido de fútbol o bien le pedían permiso para encontrarse con una chica, en lugar de llamarle por teléfono o buscarla por internet.

\section{En Bachillerato...}

Paco tenía una máquina mecánica Olivetti clásica cuando estaba en secundaria y, como era el único estudiante en casa, solo él la utilizaba:

... para hacer tareas porque, justo mi generación yo creo que fue la generación de transición, o sea las tareas de la Secundaria yo las hice en máquina de escribir [mju] y, podías en el taller de Secundaria en el sistema mexicano, podías escoger ya sabes [ah] o Cocina o Electrónica o taquimecanografía [taquimecanografía, si] Claro, entonces eh: bueno, tenías que llevar una clase cada mes de prueba, me parece, o algo así, o sea, eh digamos que tú, en mi Secundaria tenías que tomar una clase de cada cosa para que luego pudieras decidir. [PA/2/10]

Al final Paco eligió el taller de electrónica, pero una vez al mes asistía al de taquimecanografía y se percató de las ventajas de utilizar todos los dedos al escribir, práctica que decidió mejorar al utilizar la computadora:

... yo mismo conseguí un libro y ahora sé, en serio, para mecanografiar ¿no?, me puse a hacer los ejercicios [pero ya en el ordenador] en ordenador. [PA/2/11]

Pasó de manera directa de la máquina mecánica a la computadora. Tuvo su primera computadora a finales del bachillerato (tendría unos 17 o 18 años). Cuando sus padres le compraron la computadora, no sabía utilizarla por lo que decidió tomar un curso básico de informática. Esencialmente, el uso que le daba era como procesador de textos, para hacer sus tareas. Cuando ingresó a la carrera de veterinaria -donde solo estudió dos años- no la utilizaba mucho, porque no la consideraba necesaria para el tipo de tareas que le pedían. Luego renuncia a veterinaria e ingresa a la carrera de comunicación y es cuando comienza a tener una relación más frecuente con la máquina. 
Tuvo contacto con internet en 1994, cuando entró a trabajar a una universidad. Él mismo quedó sorprendido al percatarse que tardó dos años en sacar su primera cuenta de correo electrónico y lo hizo porque comenzó a dar clases. Tenía que bajar información y compartir el material de lectura con sus estudiantes:

... por primera vez, vi esta cosa maligna, que era el Internet, y me resulta para mi eh sorprendente que mi primer correo elec...o sea mi primera cuenta de correo, la obtuve en, en el 86 , o sea digamos eh: perdón en 96 [PA/1/3]

Nos cuenta cómo fue que se enteró de la existencia del correo electrónico. Sucedió cuando estuvo por primera vez en España en 1997:

... tomé un máster aquí en, en España, en Andalucía y en una conversación cuando estábamos por despedirnos los amigos fraternos que habíamos hecho aquí y estábamos por vol...- por volver cada quién a su país, una chica me dio su teléfono y me escribió algo que yo no pude reconocer [ah:] y le dije ¿esto qué es? y entonces descubrí que eso era un, una cuenta de correo [qué me está dando, una clave] mju, sí, claro, además decía como era Hotmail el más este: popular ¿no? [aja] le puso ahí su nombre, luego el arroba, que jamás lo había visto yo, y luego hot-mail le dije ‘wow ¿a qué te dedicas?' [risas] [qué me estás insinuando] exacto [ya que nos vamos] exacto, ya es el último día, así descubrí yo los correos fijate, es que, cómo funcionan y es impresionante porque yo tenía 26, 27 años [mju] o sea que joven no era, tampoco es que hubiera entrado a la senectud como ahora verdad, pero joven no era. [PA/1/3]

Cuando llegó a México intentó abrir una cuenta. Su amiga le había dicho para qué podía utilizar el correo electrónico, pero no atinó a explicarle cómo abrir una cuenta. Considera que explicarle a alguien cómo hacer algo por internet resulta complicado y raro, que eso más bien se va descubriendo:

... cuando le pregunté 'y cómo obtengo yo una de estas cuentas', ella no atinaba a explicarme porque creo que hay una parte muy 
misteriosa, de esta tecnología de punta, entonces claro lo que podemos comprender es cómo nos relacionamos con la pantalla, pero no con el ordenador [mju] eso es: [con lo que aparece en la pantalla ¿no?] claro, claro entonces lo que a mí me decía es 'tú busca starMedia y ahí te va a salir el correo', o sea con una: un vocabulario sumamente ambiguo 'ahí te va a salir y ahí lo bajas y ahí lo abres' o sea, todo era ambiguo [y si bajo y ahí bajo qué] claro [¿no? y que qué se va a abrir ¿no?] mju, mju, sí justo y bueno pues como yo no, no no, no soy un tipo que tenga miedo de, de esto sí lo descubrí, rápido abrí, ya te imaginarás un montón de cuentas [¿sí?] si, mju, me entusiasma eso, me s...- la tecnología me entusiasma. [PA/1/3-4]

Conforme el desarrollo de los sistemas operativos iba avanzando, Paco reflexionaba al respecto:

... en un principio sí me parece que: el ordenador [muy serio] era, sí exigía que aprend...- que aprendieras a...- algoritmos ¿no? eh, eh bueno poco a poco, bueno de esto hace 12 años que Microsoft sacó el primer Windows y entonces bueno pues, todo eso se, te lo podías ahorrar, te comprabas el software y ya [ya te ahorrabas todo eso] si la interfaz ya es otra, relación. [PA/1/2]

Además de realizar sus tareas recuerda que también utilizaba la computadora para entretenerse, por ejemplo, copiaba canciones en inglés y luego las imprimía. Recordó también haber participado en algunos foros de chat. Paco muestra una considerable preocupación por la capacitación en el uso de la computadora y estaba informado de dónde y quiénes estaban certificados para dar estos cursos. Tenía la idea de que para poder utilizar la computadora había que tener conocimientos de diseño en informática:

... lo que se trataba era de formar a: in...- a i...- técnicos informáticos [mju] sólo ahí entiendo que en el país sólo ahí se ofreció ese tipo de capacitación del MS-DOS, después cuando Microsoft saca su software, su sistema operativo ya no era necesario tomar clases [risas] porque entonces fue amigable ino? [Claro] fue una manera amable de, de, de tener un software contigo [mju] pero 
antes de que surgiera sur...- surgiera Microsoft la única institución donde podías tomar estas clases de manera pública era CONALEP, la otra es que aquellas personas que se sintieran atraídos por el ordenador eh, tenían que tomar una clase [mju] ¿no? y yo la tomé. [PA/1/1]

Cuando aparece Windows y conoce el paquete de Office tuvo la intención de tomar clases, pero al final lo consideró innecesario ya que el sistema era bastante amigable. Tenía la idea de que existía un perfil de usuario al cual le serían útiles estos cursos de computación, pero él no se consideraba de este tipo, se sentía bastante confiado para autocapacitarse.

Sus dos primeras computadoras fueron de escritorio, cuando tuvo un ingreso fijo decidió comprarse una portátil. La primera vez que cambió de máquina fue porque se mudó de ciudad, en otra ocasión fue por motivos de portabilidad; en general, las razones para cambiar de modelo han sido o porque se descomponen o bien porque se ha percatado de que el mercado le ofrece novedades y considera que el suyo se vuelve obsoleto.

Los alcances de la tecnología le parecen impresionantes y se siente muy afortunado de poder vivir en esta etapa de la historia de la humanidad. Considera que el tiempo y el espacio ya no pueden ser pensados igual que antes y esta parte le encanta. Trata de relativizar el contacto virtual; no le agrada mucho este tipo de relaciones, pero considera que en ciertos momentos y con ciertas personas es mejor la interacción virtual que la física; le abruma saber que puede relacionarse de manera exponencial con las personas conocidas de sus conocidos y conocidas, y opina que, de ninguna manera, una forma de relación sustituye a la otra, porque las concibe de manera distinta.

\section{Reflexiones finales}

Estas reflexiones incluyen las experiencias de las 10 personas entrevistadas, quienes destacan la conexión de la formación en mecanografía o el uso de la máquina de escribir con el posterior acceso a las computadoras e internet. De hecho, parece que la máquina de escribir se presenta como una práctica intermedia o facilitadora para el uso de la computadora. También puede concebirse que la computadora -en la época y en el contexto de estos usuarios- se utilizó primero como 
máquina de escribir, es decir, utilizándola sin conexión a internet y como procesador de texto simplemente.

Algunas de estas personas vivieron en propia piel el paso de una máquina de escribir mecánica a una electrónica. Fue común que se recibiera instrucción formal de taquimecanografía por parte de la escuela, y que llegaran a entregar sus trabajos escolares con máquina de escribir o escritos mano.

Aun cuando fuera por casualidad, su primer contacto con la computadora fue a través de la escuela. Adquirir esta nueva tecnología se volvió un inconveniente, debido al costo que suponía en ese momento; la solución era ir al cibercafé -de moda en ese entonces- o a casa de alguna amistad o familiar. En algún punto, los padres tomaron conciencia de que era una necesidad contar con una computadora en casa, porque se gastaba mucho en la renta de equipo, en las impresiones, y porque suponía una molestia el ir a casas ajenas a hacer las tareas.

Las familias hacían un esfuerzo por comprar una computadora -a plazos o a través de conocidos, es decir, no todos pudieron adquirir un equipo nuevo-; en un principio también era compartido con los hermanos o primos. En el caso de dos de nuestras informantes, la computadora de casa se encontraba en el cuarto de sus hermanos varones, lo que impedía un fácil acceso para ellas.

Fue a mediados y finales de los 90 cuando tuvieron su primer acercamiento con internet, a través de alguna institución educativa -bachillerato, universidad, cursos privados- o en el ambiente laboral. En esa época la única compañía telefónica en México ofrecía facilidades para adquirir computadoras y el servicio de conexión a internet, que suponía un gasto extra y problemas de comunicación. No existía la telefonía móvil y como el servicio se proporcionaba a través de la línea telefónica, resultaba imposible comunicarse a casa, si alguien estaba conectado a internet en ese momento, lo que provocaba conflictos familiares, ya que la llamada no entraba.

Las cuentas de correo electrónico aparecieron cuando se encontraban entre el bachillerato y la universidad. En un principio no quedaba muy claro cuál era su funcionalidad. De hecho algunos servidores de correo les resultaban dudosos (como el Hotmail) y destacan la intervención de alguien más para poder abrir una cuenta o para empezar a utilizarla de manera frecuente (una amiga, una novia, un hermano o hermana). 
El aprendizaje informal en contextos vernáculos (ya fuera en casa propia, de amigos o amigas, en cibercafés, casa de cultura, etc.) también jugó un papel relevante. Como era una tecnología novedosa sentían curiosidad y exploraban sus funciones a través de actividades lúdicas: se grababan sonidos, se transcribían letras de canciones, se escribían cartas y jugaron con los primeros videojuegos.

Asimismo, surgieron necesidades sociales de aprendizaje. El contexto donde se desarrollaban, las amistades que frecuentaban y las exigencias del mundo académico y laboral, comenzaron a imponerse para que, poco a poco, fueran insertándose y familiarizándose con las computadoras.

La escuela fue la encargada de la primera y única instrucción formal que recibió una parte de este grupo, aunque para la totalidad fue una enseñanza muy básica y precaria, que no se valora positivamente. Por este motivo, la mayoría de informantes tomó clases particulares para ampliar sus conocimientos. A pesar de este esfuerzo por aprender, parece que esta formación tampoco tuvo resultados productivos porque, o no recuerdan lo que aprendieron, o no tienen claro cómo se inició este acercamiento, o bien utilizaron equipos y programas que se volvieron obsoletos en poco tiempo y lo aprendido no tuvo aplicaciones.

Por otro lado, hubo quienes no tomaron clases particulares y se animaron a aprender por cuenta propia. En este caso, no estuvieron solos en esta aventura, puesto que siempre aparece un colega, una novia, un amigo o un "experto" que comparte el saber con el sujeto aprendiz, de una manera generosa y cooperativa.

Desde sus primeros acercamientos a esta tecnología se corría el rumor -recuerdan- de que en un futuro sería indispensable saber utilizar las computadoras. No se tenía muy claro por qué, ni para qué, pero se sospechaba que sería importante y para eso había prepararse. Ahora la mayoría no concibe su vida sin la computadora -y sin internet-, sobre todo estando fuera de su país, porque supone un acercamiento con sus familias a bajo costo. Resulta ser una herramienta indispensable, vital y necesaria para cumplir su principal objetivo: terminar su posgrado o realizar su trabajo.

Además de lo anterior, es una generación que advierte ciertos peligros en su uso constante: daños a la salud, enajenamiento, pérdida en la habilidad para relacionarse con otra gente a nivel personal. Y 
también se sienten privilegiados y privilegiadas de poder ser testigos y protagonistas de todos estos cambios, tanto personales como sociales.

\section{Referencias}

Barton, D., y Hamilton, M. (1998). Literacy practices. En D. Barton, M. Hamilton, y R. Ivanic. (Eds.), Situated literacies. Reading and Writing in Context (7-15). Londres: Routledge.

Barton, D., y Hamilton, M. (2004). La literacidad entendida como práctica social. En V. Zavala,

M. Niño-Murcia, y P. Ames (Eds.), Escritura y sociedad. Nuevas perspectivas teóricas y etnográficas (109-139). Perú: Red para el desarrollo de las ciencias sociales en el Perú.

Camitta, M. (1993). Vernacular writing: varieties of literacy among Philadelphia High School Students. En B. Street (Ed.), Cross-cultural approaches to literacy (228-246). New York: Cambridge University Press.

Gee, J. (1990). Social linguistics and literacies. New York: The Falmer Press.

Gee, J. (1999). The New Literacy Studies and the "Social Turn". Recuperado de: http://eric.ed.gov/ERICWebPortal/search/ detailmini.jsp?_nfpb=true\&_\&ERICExtSearch_SearchValue_0=ED442118\&ERICExtSearch_SearchType_0=no\&accno $=$ ED442118

Gee, J. (2000). The New Literacy Studies. From 'socially situated' to the work of the social. En

D. Barton, M. Hamilton, y R. Ivanic (Eds.), Situated literacies. Reading and Writing in Context (180-196), Nova York: Routledge.

Heath, S. (1983). Ways with words: Language, life and work in communities and classrooms. Cambridge: Cambridge University Press.

Kalman, J. (1999). Writing on the Plaza: mediated literacy practices among scribes and clients in Mexico city. Cresskill: Hampton Press.

Kalman, J. (2004). Saber lo que es la letra: Una experiencia de lectoescritura con mujeres mixquic. Biblioteca para la actualización del maestro. México: SEP - Siglo XXI.

Kress, G. (2003). Literacy in the New Media Age. Londres: Routledge. 
Lankshear, C., Gee, P., Knobel, M., y Searle, C. (1997). Changing Literacies. Great Britain: Open University Press.

Scribner, S., y Cole, M. (1981). The Psychology of Literacy. Cambridge: Harvard University Press.

Street, B. (1984). Literacy in theory and practice. Cambridge: Cambridge University Press.

Street, B. (1993). Cross cultural approaches to literacy. Cambridge: Cambridge University Press.

Street, B. (1995). Social literacies: critical approaches to literacy development, ethnography and education. New York: Longman. 